\title{
Study of a Simplified Model for DFIG-Based Wind Turbines
}

\author{
F. K. A. Lima \\ non-Member, IEEE \\ COPPE/UFRJ \\ Brazil \\ kleber@coe.ufrj.br
}

\author{
A. Luna \\ Student Member, IEEE \\ REES/UPC \\ Spain \\ luna@ee.upc.edu
}

\author{
P. Rodríguez \\ Member, IEEE \\ REES/UPC \\ Spain \\ prodriguez@ee.upc.edu
}

\author{
E. H. Watanabe \\ Senior Member, IEEE \\ COPPE/UFRJ \\ Brazil \\ watanabe@coe.ufrj.br
}

\author{
M. Aredes \\ Member, IEEE \\ COPPE/UFRJ \\ Brazil \\ aredes@ufrj.br
}

\begin{abstract}
In the study of the dynamical behavior of doublyfed induction generators (DFIG), for wind power applications, the use of reduced order models is useful in order to design specific control strategies for wind power plants as well as to obtain lightweight computing simulations. Within this field this paper presents a new dynamic model for wind turbines, based on DFIG, able of representing accurately its behavior during both the steady state and the transient of the grid voltage. As it will be proven this model permits to perform an accurate analysis of the system when there is a voltage dip in the grid. In the following a theoretical study of this model will be carried out and the accuracy of its performance will be tested under different conditions, by means of PSCAD/EMTDC simulations, in order to show its reliability. Finally the reliability of the simplified model will be tested in a scaled experimental setup.
\end{abstract}

Index Terms -- Wind power generation, Power system faults, Current control, AC generators, Electric variables control.

\section{INTRODUCTION}

The increasing capacity of the installed wind power generation facilities linked to the electrical network have made necessary to redesign the existing grid code requirements (GCR) [1], [2]. Between the new demands, those that concern the capability of wind power generators to remain connected to the grid, in case of grid voltage sags, have gained a great importance [3]-[5]

This feature, known as low voltage ride through capability [6], is of special interest in wind power systems based on doubly-fed induction generators (DFIGs). In this sort of machines the voltage drop in the stator windings that occurs when there is a voltage sag in the network produces a sudden change in the stator flux of the DFIG. As a consequence of this transient the currents in the stator increases rapidly, experiencing an overcurrent that is transmitted to the rotor windings. These overcurrents, which can be up to three times the nominal value [7] can damage the rotor and stator windings but its consequences are specially critical for the semiconductors of the rotor side converter (RSC), that can reach a thermal breakdown.

Improving the behavior of DFIG in faulty scenarios, in order to fulfill the new LVRT requirements, has become an issue of great interests for wind turbines manufacturers. Regarding this topic the use of reduced order models to prove the conformity with the grid code requirements and to design specific control strategies for such conditions is becoming a powerful tool for wind turbine manufacturers, who need to model a large number of wind turbines connected to a distributed generation grid. However the design of simplified models should be carefully treated in order to guarantee their reliability. The layout of a WT based on doubly-fed induction generator is shown in Fig.1.

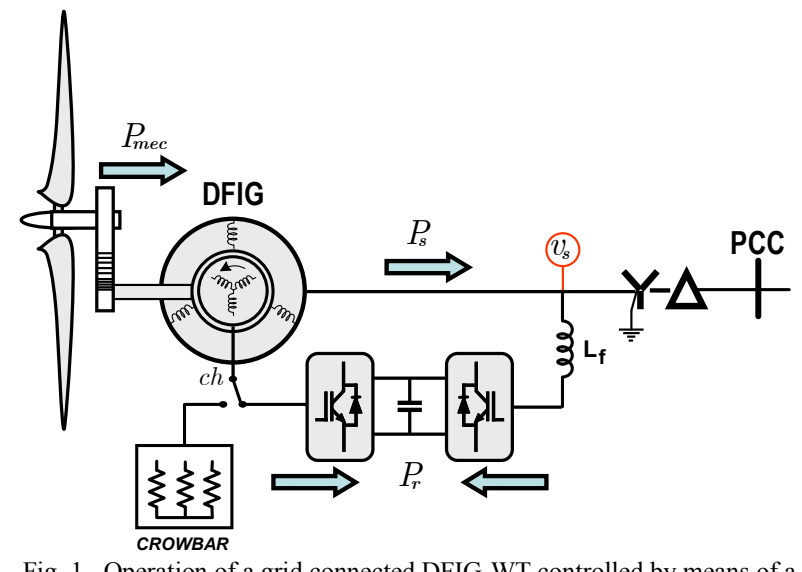

Fig. 1. Operation of a grid connected DFIG-WT controlled by means of a back to back power converter.

The aim of this work is to present a simplified model of a DFIG-WT able to simulate accurately the behavior of the system if compared with the classical fifth-order model. In the following a theoretical study of this model will be carried out and the accuracy of its performance will be tested under faulty scenarios, by means of PSCAD/EMTDC simulations, in order to show its reliability.

\section{MODELING OF THE GENERATOR}

The objective of this section will be focused on finding a simple relationship between the state space variables that could permit to predict the behavior of DFIG under fault conditions.

\section{A. Reference Frame System}

In this paper the rotor side controller has been implemented considering a field oriented control (FOC) philosophy in the $d q$ reference frame. In this kind of systems the $d q$ axis are aligned with the stator flux, as it can be noticed from Fig. 2. This reference frame, known as 
synchronous reference frame (SRF), is useful in order to reduce partially the complexity of the mathematical equations that describe the system.

As it can be deducted from Fig. 2, and due to the low leakage stator inductance, the voltage of the stator $v_{s}$, can be considered to be $90^{\circ}$ leaded with respect the statoric flux, and hence almost completely aligned with the in-quadrature axis, $q$, while the magnetizing current in the stator have a single component in the $d$ axis.

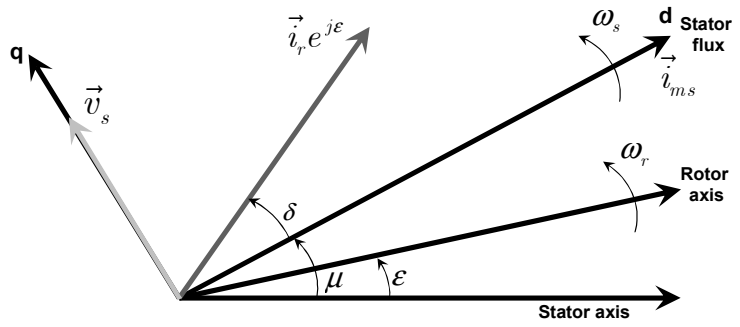

Fig. 2. Vector diagram in the $d q$ synchronous reference.

\section{B. Voltage and Magnetic Flux Equations}

The voltage and magnetic flux of the stator in a fifth order model can be written as:

$$
\begin{gathered}
v_{d s}=R_{s} i_{d s}+\frac{d \lambda_{d s}}{d t}-\omega_{s} \lambda_{q s}, \\
v_{q s}=R_{s} i_{q s}+\frac{d \lambda_{q s}}{d t}+\omega_{s} \lambda_{d s}, \\
\lambda_{d s}=L_{s} i_{d s}+L_{m} i_{d r}, \\
\lambda_{q s}=L_{s} i_{q s}+L_{m} i_{q r} .
\end{gathered}
$$

In an analogous way the equations that describe the dynamics of the voltage and magnetic flux at the rotor are:

$$
\begin{gathered}
v_{d r}=R_{r} i_{d r}+\frac{d \lambda_{d r}}{d t}-\omega_{s l i p} \lambda_{q r} \\
v_{q r}=R_{r} i_{q r}+\frac{d \lambda_{q r}}{d t}-\omega_{s l i p} \lambda_{d r} \\
\lambda_{d r}=L_{r} i_{d r}+L_{m} i_{d s} \\
\lambda_{q r}=L_{r} i_{q r}+L_{m} i_{q s}
\end{gathered}
$$

Where $\lambda_{s}$ and $\lambda_{r}$ are the stator and rotor magnetic flux; $L_{s}$, $L_{r}$ and $L_{m}$ are the stator, rotor and magnetizing inductances; $v_{s}$ and $i_{s}$ are the stator voltages and currents; $v_{r}$ and $i_{r}$ are the rotor voltages and currents; $R_{r}$ and $R_{s}$ are the rotor and stator resistances; $\omega_{s}$ and $\omega_{r}$ are the synchronous and rotating angular frequencies, respectively, and $\omega_{\text {slip }}$ is the slip frequency.

\section{Simplified Proposed Model for DFIG}

Considering that the system described by (1) and (2) is linear, assuming that the magnetic circuit of the DFIG is linear, and later applying the Laplace transformation it is possible to obtain the following statoric currents in the synchronous reference frame:

$$
\begin{aligned}
& i_{d s}=\frac{\left(L_{s} s+R_{s}\right) v_{d s}+\omega_{s} L_{s} v_{q s}}{\left(L_{s}^{2} s^{2}+2 L_{s} R_{s} s+R_{s}^{2}+\omega_{s}^{2} L_{s}^{2}\right)}- \\
& -\frac{\left(L_{s} s^{2}+R_{s} s+\omega_{s}^{2} L_{s}\right) L_{m} i_{d r}-R_{s} \omega_{s} L_{m} i_{q r}}{\left(L_{s}^{2} s^{2}+2 L_{s} R_{s} s+R_{s}^{2}+\omega_{s}^{2} L_{s}^{2}\right)}, \\
& i_{q s}=\frac{-\omega_{s} L_{s} v_{d s}+\left(L_{s} s+R_{s}\right) v_{q s}}{\left(L_{s}^{2} s^{2}+2 L_{s} R s_{s}+R_{s}^{2}+\omega_{s}^{2} L_{s}^{2}\right)}- \\
& -\frac{R_{s} \omega_{s} L_{m} i_{d r}+\left(L_{s} s^{2}+R_{s} s+\omega_{s}^{2} L_{s}\right) L_{m} i_{q r}}{\left(L_{s}^{2} s^{2}+2 L_{s} R_{s} s+R_{s}^{2}+\omega_{s}^{2} L_{s}^{2}\right)} .
\end{aligned}
$$

The equations (3) and (4) can be simplified considering that in a field oriented control system the stator flux is aligned with the $d q$ reference frame, and hence its quadrature component is null. Besides, and assuming that the leakage inductance value is low, the stator voltage vector can be considered to be almost aligned with the in-quadrature axis. Taking into account that in the second term of both expressions the crossed terms of the rotor current, $i_{d r}$ and $i_{q r}$, are negligible, due to the low value of the $R_{s} \omega_{s} L_{m}$ coefficient if compared with the multiplicative factor $\left(L_{s} s^{2}+R_{s} s+\omega_{s}^{2} L_{s}\right) L_{m}$, and considering that the quotient shown in (5) is almost equal to one:

$$
\frac{\left(L_{s} s^{2}+R_{s} s+\omega_{s}^{2} L_{s}\right)}{\left(L_{s} s^{2}+2 R_{s} s+\omega_{s}^{2} L_{s}\right)} \cong 1 .
$$

The final simplified model can be obtained as detailed in (6) and (7).

$$
\begin{gathered}
i_{d s}=\frac{1}{L_{s}} \frac{\omega_{s}}{s^{2}+2\left(R_{s} / L_{s}\right) s+\omega_{s}^{2}} v_{q s}-\frac{L_{m}}{L_{s}} i_{d r}, \\
i_{q s}=\frac{1}{L_{s}} \frac{s+R_{s} / L_{s}}{s^{2}+2\left(R_{s} / L_{s}\right) s+\omega_{s}^{2}} v_{q s}-\frac{L_{m}}{L_{s}} i_{q r}
\end{gathered}
$$

In both equations, the rotor current and the stator voltage appear as the input variables, as the first one is fixed by the rotor side converter while $v_{q s}$ depends on the grid behavior.

As it can be concluded from (6) and (7), any variation in the stator voltage introduce oscillations in the $d q$ components of the stator currents in the synchronous reference frame. The frequency of such oscillation is equal to the grid frequency and its damping is very poor, due to the low value of the stator resistance, $R_{s}$ (generally around $0.005 \mathrm{pu}$ )

This phenomenon can be specially noticed when voltage sags occur. If there is a balanced voltage sag, the stator currents in $d q$ oscillate at $\omega_{s}$, additionally, if the sag is unbalanced, the negative sequence components that appear 
forces oscillations with a frequency equal to $2 \omega_{s}$ in $v_{d s}$ and $v_{q s}$, that shall be added to the $\omega_{s}$ ones, which are generated by the sudden change in the positive sequence magnitude.

The steady state equation of the simplified model described in (6) and (7) are depicted in (8) and (9).

$$
\begin{gathered}
i_{d s}=\frac{1}{L_{s} \omega_{s}} v_{q s}-\frac{L_{m}}{L_{s}} i_{d r}, \\
i_{q s}=\frac{R_{s}}{L_{s}^{2} \omega_{s}^{2}} v_{q s}-\frac{L_{m}}{L_{s}} i_{q r} .
\end{gathered}
$$

Analyzing (9), it can be concluded that the multiplicative factor of the in-quadrature component of the stator's voltage tends to zero. Thus, and considering that $R_{s} \ll L_{s}^{2} \omega_{s}^{2}$, this equation can be reduced to:

$$
i_{q s}=-\frac{L_{m}}{L_{s}} i_{q r}
$$

In equation (9), $i_{q s}$, reveals the linear dependence between the stator and rotor current components on the in-quadrature axis.

On the other hand, the final value of $i_{d s}$ in (8) depends upon two terms. The first one, considering the steady state conditions, describes its relationship with the magnetization's current, while the second depends on the rotor's direct current component.

\section{Simulation Results}

The simulation results, depicted in Fig. 4(a) and Fig. 4(b), show the response of the stator and rotor currents in the $d q$ axes when a balanced voltage sag at the point of common coupling (PCC), present in Fig. 3, occurs at $\mathrm{t}=2 \mathrm{~s}$ and last after $200 \mathrm{~ms}$.

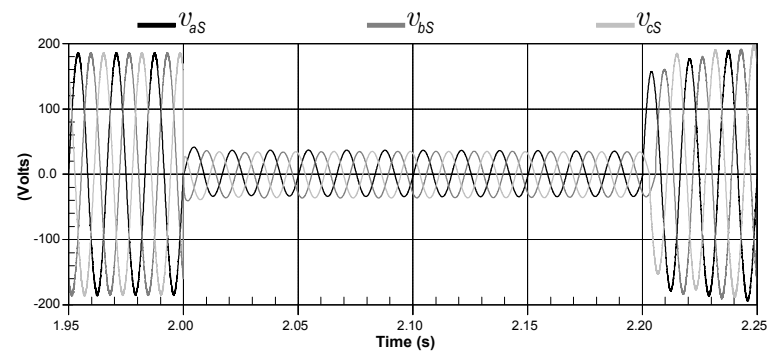

Fig. 3. Balanced voltage sag.

The simulation results, depicted in Fig. 4(a) and Fig. 4(b), show the response of the stator and rotor currents in the $d q$ axes when a $80 \%$ depth balanced voltage sag at the stator winding occurs at $t=2 \mathrm{~s}$ and last after $200 \mathrm{~ms}$.

In both figures the output of a classical fifth order model and the proposed simplified model are shown together, in order to prove their relationship.
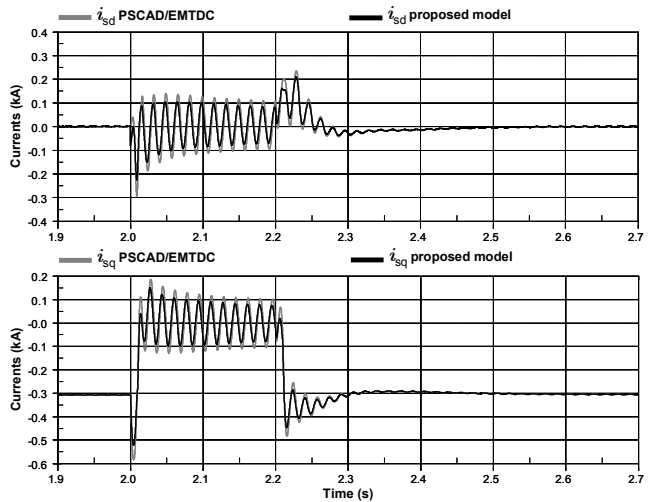

(a) Stator currents
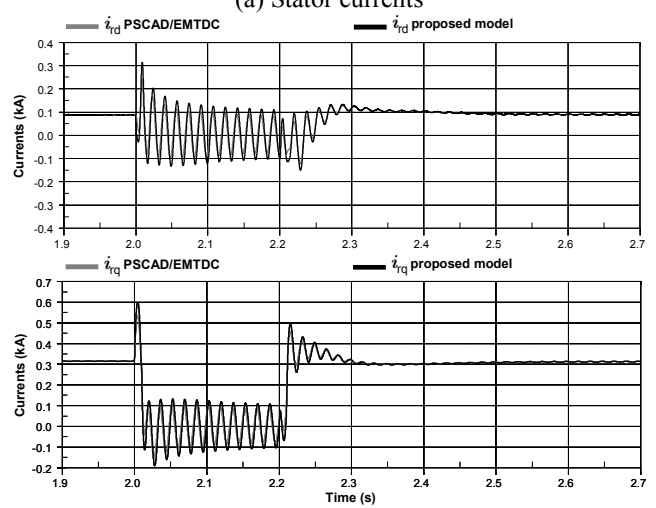

(b) Rotor currents

Fig. 4. Transient response of the stator and rotor currents with the proposed simplified model in front of the traditional fourth order model, when a $80 \%$ depth three phase balanced fault is applied at $t=2.0 \mathrm{~s}$ and cleared after $200 \mathrm{~ms}$.

As it can be easily realized, these results permit to conclude that the proposed simplified model describes the DFIG's behavior accurately.

\section{EXPERIMENTAL RESULTS}

The accuracy of the simplified model has been tested as well in an experimental setup. The parameters of the experimental plants are shown in Table II at the end of the paper.

In a first experiment, the reactive power setpoint at the rotor side converter change from 0 var to 1300 var. As a consequence of this variation the $i_{r d}$ component changes giving rise to a change in the $i_{s d}$ variable at the stator side. The performance of this current is depicted in the following figure, where the response of the real measured current with the simplified model prediction is compared.

As it can be noticed in Fig. 5(b), the dynamical behaviour of the current is perfectly tracked, giving rise to the same time constant.

A second similar experiment was also carried out, but this time the active power setpoint was changed from $0 \mathrm{~W}$ to 
$1400 \mathrm{~W}$. In this case this reference jump produce a change in the $i_{r q}$ component, that is translated into a $i_{s q}$ step. The behavior of the real plant and the estimated model are shown in Fig. 6. As it can be deducted from the figure, like in the previous case the model tracks accurately the real value.

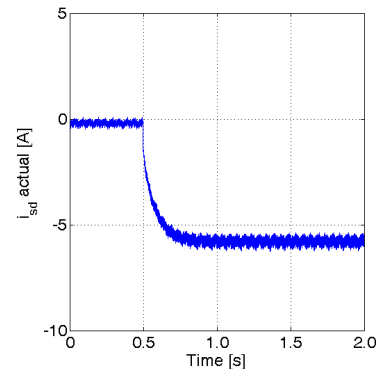

(a)

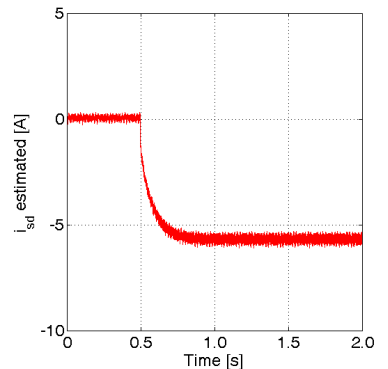

(b)
Fig. 5. Transient in $i_{s d}$ the current as a consequence of a reactive power setpoint jump. (a) Measured $i_{s d}$ current at the experimental setup; (b) Estimated $i_{s d}$ current by the simplified model.

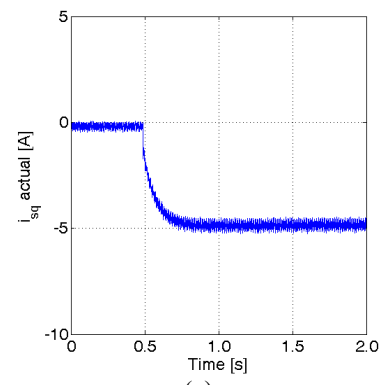

(a)

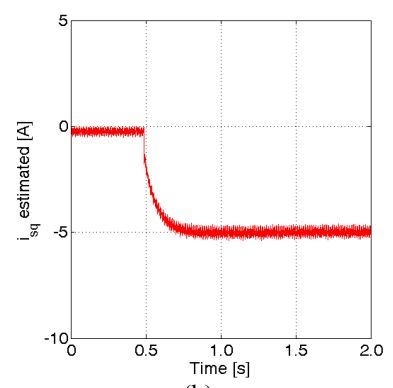

(b)
Fig. 6. Transient in $i_{s q}$ the current as a consequence of a active power setpoint jump. (a) Measured $i_{s q}$ current at the experimental setup; (b) Estimated $i_{s q}$ current by the simplified model.

Fig. 7 and Fig. 8 show the behavior, for those experiments, of both stator and rotor currents in $d q$ reference frame, which are in accordance with (8) and (10), respectively.

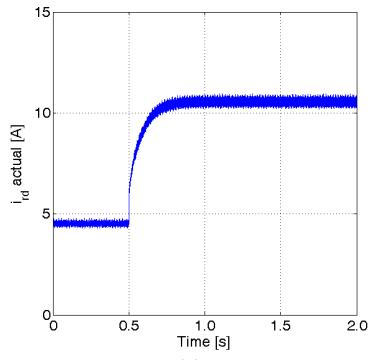

(a)

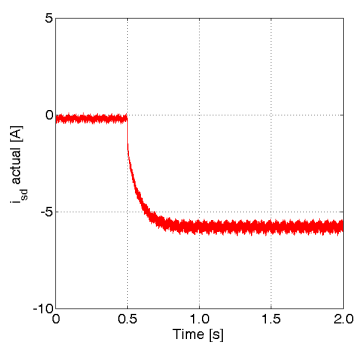

(b)
Fig. 7. Transient in both $i_{r d}$ and $i_{s d}$ currents as a consequence of a reactive power setpoint jump. (a) Measured $i_{r d}$ current at the experimental setup; (b) Measured $i_{s d}$ current at the experimental setup .

In this study case, the DFIG was injecting only $2 \mathrm{~A}$ of reactive power to the network. Hence the $i_{s d}$ current was null while the total current was aligned with the $q$ axis.
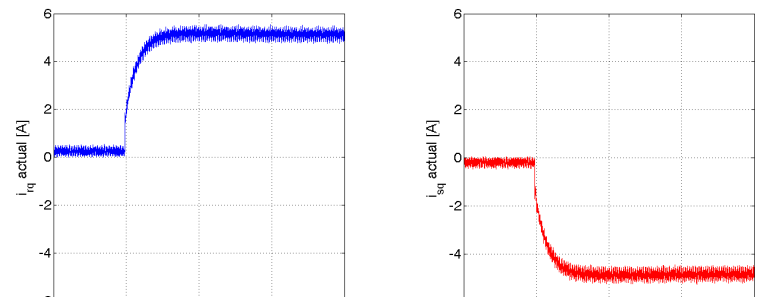

This statement can be easily proven by means of Fig. 9 and Fig. 10.

In Fig. 9, it can be clearly noticed how the transient in the voltage give rise to an overcurrent, due to the sudden flux change, that appears also when the fault is cleared. In Fig. 10, the same phenomena stand out.

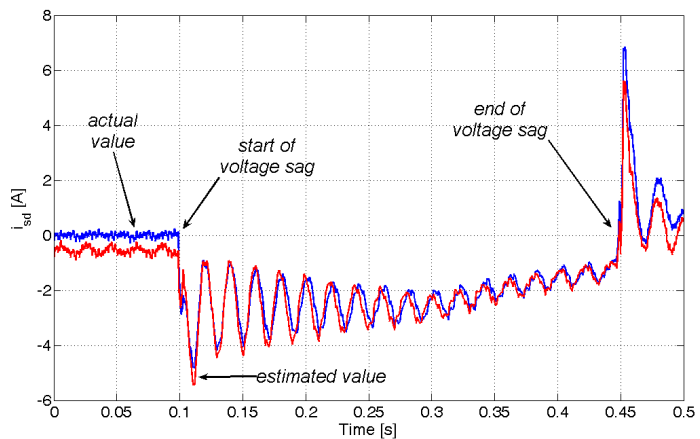

Fig. 9. Comparison of the estimated and real value of $i_{s d}$ when there is a voltage drop in the stator's voltage.

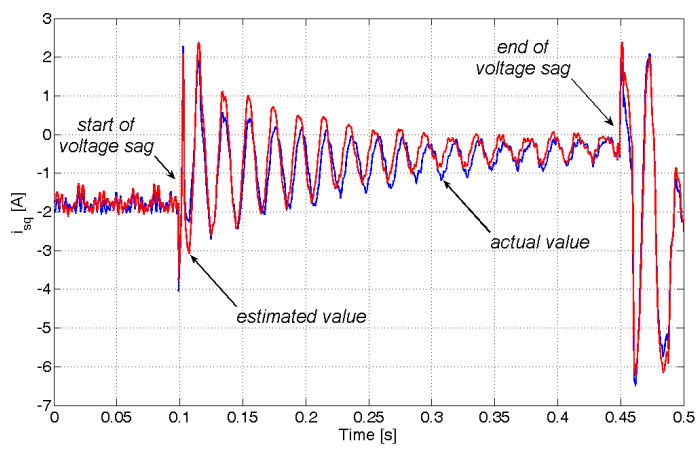

Fig. 10. Comparison of the estimated and real value of $i_{s q}$ when there is a voltage drop in the stator's voltage.

\section{CONCLUSION}

The simplified model presented in this work permits to carry out a straightforward analysis of the DFIG's performance when transients in the rotor current or in the stator voltage occur. These transient conditions correspond mainly to:

- Changes in the active/reactive power delivery setpoint 
- Voltage drops due to grid faults.

This model can be useful when simulating large scale wind power applications, although this theme is not treated in this paper, as it is possible to emulate the behaviour of a DFIG by means of two simple second order transfer functions. Therefore simulating the behaviour of several DFIG-WTs would not take as much computational time as when using the fifth order model.

In addition, the simplified model permits to design simple strategies oriented to enhance the performance of DFIGs under sag conditions. Although the same conclusions could be reached using a more complex model this simplified version enables to conduct a more intuitive estimation about the behaviour of the system.

\section{APPENDIX}

Table I gathers the parameters of the doubly-fed induction generator used in the simulations of this paper.

TABLE I

MACHINE PARAMETERS

\begin{tabular}{|c|c|}
\hline \multicolumn{2}{|c|}{ MACHINE PARAMETERS } \\
\hline DFIG characteristics & Values \\
\hline Rated power & $100 \mathrm{kVA}$ \\
\hline Rated stator voltage & $220 \mathrm{~V}$ \\
\hline Rated rotor voltage & $220 \mathrm{~V}$ \\
\hline Rated stator frequency & $60 \mathrm{~Hz}$ \\
\hline Stator resistance & $2.6 \mathrm{~m} \Omega$ \\
\hline Rotor resistance & $2.9 \mathrm{~m} \Omega$ \\
\hline Stator leakage inductance & $138.66 \mu \mathrm{H}$ \\
\hline Rotor leakage inductance & $141.22 \mu \mathrm{H}$ \\
\hline Magnetizing inductance & $5.6 \mathrm{mH}$ \\
\hline Angular moment of inertia $(\mathrm{J}=2 \mathrm{H})$ & $0.5 \mathrm{pu}$ \\
\hline Poles pairs & 1 \\
\hline
\end{tabular}

The parameters of the experimental plants are shown in the Table II.

TABLE II

\begin{tabular}{l|l}
\multicolumn{1}{c}{ SPECIFICATION OF THE EXPERIMENTAL SETUP } \\
\hline \multicolumn{1}{c}{ DFIG parameters } & \multicolumn{1}{c}{ Values } \\
\hline Rated power & $7.5 \mathrm{kVA}$ \\
Rated stator voltage & $220 \mathrm{~V}$ \\
Rated rotor voltage & $220 \mathrm{~V}$ \\
Rated stator frequency & $50 \mathrm{~Hz}$ \\
Stator resistance & $0.462 \Omega$ \\
Rotor resistance & $0.473 \Omega$ \\
Stator leakage inductance & $3.93 \mathrm{mH}$ \\
Rotor leakage inductance & $3.93 \mathrm{mH}$ \\
Magnetizing inductance & $130.4 \mathrm{mH}$ \\
Turns ratio & 1 \\
Poles pairs & 2 \\
\hline \multicolumn{1}{c}{ Power converters } & Values \\
\hline Rated power & $5 \mathrm{kVA}$ \\
Rated voltage & $780 \mathrm{~V}$ \\
Rated current & Values \\
\hline
\end{tabular}

\begin{tabular}{l|l}
\hline DC voltage & $500 \mathrm{~V}$ \\
Capacitance & $4700 \mu \mathrm{F}$ \\
\hline
\end{tabular}

\section{ACKNOWLEDGMENT}

This work was supported in part by the CNPq under numbers 473294/2004-4 and 141079/2005-3, by FAPERJ and by the Ministerio de Ciencia y Tecnologia of Spain under the project ENE2008-06588-C04-03/ALT.

\section{REFERENCES}

[1] I. Erlich, W. Winter, and A. Dittrich, "Advanced grid requirements for the integration of wind turbines into the German transmission system", Power Engineering Society General Meeting, Jun. 2006, 7 pp.

[2] A. Morales, X. Robe, M. Sala, P. Prats, C. Aguerri, and E. Torres, "Advanced grid requirements for the integration of wind farms into the Spanish transmission system", IET Renewable Power Generation, vol. 2, no 1, Mar. 2008, pp. 47-59.

[3] E-ON Netz GmbH, "Grid code - High and extra high voltage", Apr. 2006, <http://www.eon-netz.com>.

[4] National Grid Electricity Transmission, "The grid code:Revision 31", in United Kingdom no 3, Oct. 2008, http://www.nationalgrid.com/uk>.

[5] Comisíon Nacional de Energía, "PO-12.3 Requisitos de respuesta frente a huecos de tension de las instalaciones eolicas", in Spanish Oct. 2006.

[6] P. Krause, O. Wasynczuk, and S. Sudhoff, Analysis of Electric Machinery and Drive Systems, 2nd ed. New York: Wiley-IEEE Press, 2002.

[7] B. M. Buchholz, Z. A. Styczynski, and W. Winter, "Dynamic simulation of renewable energy sources and requirements on fault ride through behavior", IEEE Power Engineering Society General Meeting, 2006, 18-22 Jun. 2006, 7 pp. 